www.jmscr.igmpublication.org

Impact Factor (SJIF): 6.379

Index Copernicus Value: 79.54

ISSN (e)-2347-176x ISSN (p) 2455-0450

crossrefDOI: https://dx.doi.org/10.18535/jmscr/v6i12.31

Journal Of Medical Science And Clinical Research

IGM Publication

An Official Publication of IGM Publication

\title{
A Cross Sectional Study on Association between Body Mass Index and Hypertension Status among above 40 years old in Rural South India
}

\author{
Authors \\ Dr R. Gouthaman ${ }^{1}$, Dr A. John.William Felix ${ }^{2}$, Dr K. Senthil Kumar ${ }^{3}$, Dr S. Yoganand ${ }^{3}$ \\ ${ }^{1}$ Reader, Department of Community Medicine, Rajah Muthiah Medical College \& Hospital \\ ${ }^{2}$ Professor, Department of Community Medicine, Rajah Muthiah Medical College \& Hospital \\ ${ }^{3}$ Post graduate, Department of Community Medicine, Rajah Muthiah Medical College \& Hospital \\ Corresponding Author
}

Dr A. John William Felix

Department of Community Medicine, Rajah Muthiah Medical College and Hospital, Annamalai University Chidambaram, Tamilnadu, India

Email:amfelix@rediffmail.com

\begin{abstract}
As per WHO report 69 million people worldwide have hypertension. Of these $31.6 \%$ are unaware of their high blood pressure. In industrialised nations the prevalence of high blood pressure ranged from 10-20\%. India being a developing nation and there is rapid industrialisation has led to hypertension becoming a major public health problem. Industrialisation has led to change in the lifestyle and food habit of the population, coupled with physical inactivity has led to increased prevalence of obesity. The frequency of hypertension among overweight persons aged $>40$ years were $50 \%$ higher when compared with those in the normal-weight group and 100\% higher among the underweight group. This was a cross sectional study on rural population above 40 years done for a period of 7 months, in Bhuvanagiri, Cuddalore district, Tamil Nadu. The study was carried out in a sub centre of Bhuvanagiri primary health centre. The total population of the sub centre was 5832 out of which 1127 were above 40 years of age. The correlation between hypertension and BMI was done and found to be statistically significant. Also, an association between obesity and hypertension was observed.
\end{abstract}

Keywords: Hypertension, obesity, BMI, height, weight.

\section{Introduction}

WHO has stated 'You protect it, you promote it, and you extend it' as the basic principles of preventive medicine. From a global point of view the relation between hypertension and cardiovascular health is well established. Hypertension is defined by WHO as SBP equal to or greater than $160 \mathrm{~mm}$ of $\mathrm{Hg}$ and or DBP equal to or greater than $90 \mathrm{~mm}$ of $\mathrm{Hg}$. It has emerged as a worldwide health disorder ${ }^{1}$.
Hypertension is an iceberg disease, i.e., it remains hidden during most of its clinical course, but continues doing immense harm to the body silently. Hypertension is a disease with much aetiology which is cumulative rather than a single aetiology disease. Some of the factors include genetics, salt intake, obesity and physical inaction. As per a WHO report globally 69 million people worldwide have hypertension ${ }^{2}$. Of these $31.6 \%$ are unaware of their high blood pressure ${ }^{3}$. In 
industrialised nations the prevalence of high blood pressure ranged from $10-20 \%{ }^{4}$. India being a developing nation and there is rapid industrialisation has led to hypertension becoming a major public health problem ${ }^{5}$.

Industrialisation has led to change in the lifestyle and food habit of the population, coupled with physical inactivity has led to increased prevalence of obesity. The frequency of hypertension among overweight persons aged $>40$ years were $50 \%$ higher when compared with those in the normalweight group and $100 \%$ higher among the underweight group ${ }^{6}$.

Epidemiological studies carried out in urban and rural India reveals hypertension is on the rise ${ }^{4}$. The high prevalence can be explained by changing lifestyles and more exposure to stressful situations.

Several decades of epidemiological research has established that increased blood pressure is a significant contributor of cardiovascular diseases. There has been a significant increase in hypertension even among rural population, about $3 \%-15.2 \%$ of the rural population have hypertension and the prevalence of hypertension among persons $>60$ years has risen from $4 \%$ to $19 \%$ in recent years. This has contributed to high levels of morbidity and mortality and resulting in premature deaths ${ }^{7}$.

Many studies in south India point towards a higher hypertensive population. The occurrence of hypertension a decade earlier among Indians has put the population at a greater risk ${ }^{4}$. Therefore, this study aims to find the relation between obesity and hypertension in rural South India.

\section{Materials and Methods}

This was a cross sectional study covering rural population above 40 years done for a period of 7 months from June 2001 to December 2001, in Bhuvanagiri, Cuddalore district, Tamil Nadu. The study was carried out in a sub centre of Bhuvanagiri primary health centre. The total population of the sub centre was 5832 out of which 1127 were above 40 years of age.
Three visits were made to cover the absentees. In spite of the three visits investigator could not contact $30 \%$ of the population, due to various seasons.

1. Non-cooperation

2. Locked houses

3. Houses are unoccupied

4. Adults went for jobs

The tools used in the study included a mercury sphygmomanometer, stethoscope, measuring tape and weighing machine. A semi-structured questionnaire containing details like age, sex, anthropometry (height, weight) was used.

\section{Anthropometry}

Weight: The weight was measured in kilograms using a standardized portable weighing machine, upto the accuracy of one $\mathrm{kg}$ which was calibrated regularly for adjusting zero error. The weighing apparatus was standardizes periodically using standard weight of $10 \mathrm{~kg}$.

Height: The height was measured in centimetres in the standing position of the subject. It was measured by using a measuring tape up to $1 \mathrm{~cm}$ after marking the height of subject against a wall with a ruler.

Obesity: To measure obesity, the following formula was used:

Body Mass Index = Weight $/ \operatorname{Height}^{2}\left(\mathrm{~kg} / \mathrm{m}^{2}\right)$

Blood pressure was recorded using a mercury sphygmomanometer and stethoscope. The subject was asked to sit comfortably and quietly for 5 minutes. The arm relaxed and the forearm was comfortably supported with cubital fossa at heart level. The standard cuff $(12.5 \mathrm{~cm})$ was applied evenly to the exposed right upper arm. The cuff was first inflated and stethoscope was place over the right brachial artery in the cubital fossa. The point at which the first Korotkoff's sound was heard was taken as SBP, and the point at which the sound disappeared was taken as the DBP. The respondents having systolic blood pressure of equal to or more than $160 \mathrm{~mm} \mathrm{Hg}$ and diastolic blood pressure of equal to or more than $95 \mathrm{~mm} \mathrm{Hg}$ were categorized as hypertensive. Subjects already 
who were known hypertensive was also included in the study for calculating prevalence of hypertension, even if the blood pressure record was within normal range.

\section{Results}

Table no 1 shows that between 40-49 age group $82(19.2 \%)$ were hypertensives in 50-59 age group $119(40.5 \%)$ were hypertensives. In 60-69 age group $107(41 \%)$ were hypertensives. In more than 70 age group $71(48.6 \%)$ were hypertensives.

$34(6.5 \%)$ males $417(69 \%)$ females were found to be $<150 \mathrm{~cm}$ of height, $351(67.1 \%)$ males, $185(30.6 \%)$ females were 151 to $165 \mathrm{~cm}$ of height and $138(26.4 \%)$ males, $2(0.4 \%)$ females were found to be more than $166 \mathrm{~cm}$. (Table no.2)

Distribution of weight among above 40 years were showed in table no. 3 in that 103 males and 254 females were found to be weight less than $50 \mathrm{~kg}$, 344 males and 296 females were found to be between 51 to $69 \mathrm{~kg}$, 76males and 54 females were found to be more than $70 \mathrm{~kg}$.

Prevalence of hypertension among male and female study participants were shown in table no.5 in that 523 were males and 603 were female participants, the prevalence of hypertension was found to be $29 \%$ and $37.5 \%$ respectively. Prevalence of hypertension in study population was found to be $33.6 \%$ (379).

Age wise distribution of hypertensives were shown in table no. 4 in that between $40-49$ age group 82(19.2\%) were hypertensive, 50-59 age groups 119(40.5\%) were hypertensive. In 60-69 age group 107 (41\%) were hypertensive. In $\geq 70$ age group 71(48.6\%) were hypertensive. CHI SQUARE test was done and the value was 55.04, the difference was 2 and obtained a value of $\mathrm{P}<0.01$. This shows that as age increases hypertension also increases.

Table no. 4 and Table no. 5 shows the correlation between hypertension and BMI among male and female, in that $84(22.9 \%)$ were found to be hypertensive with BMI <25, 57(43.5\%) were found to be hypertensives in BMI group 25-30 and $11(44 \%)$ of hypertensives were having BMI $>30.95(27.4 \%)$ were found to be hypertensive with BMI <25, 78(48.4\%) were found to be hypertensives in BMI group 25-30 and 54(56.2\%) of hypertensives were having BMI $>30$. Chisquare test was done and the value was found to be 37.7 , with difference of 2 and having P-value of $<0.001$. it shows the statistically significant association between BMI and hypertension.

To find out association between obesity and hypertension cross table was done (table no.6). in that out of 159 obese persons 86 were found to be hypertensive and out of 968 non-obese 293 were found to be hypertensive. With odd ratio of 2.71 and $\mathrm{p}$-value of $<0.05$. it shows statistically significant association between hypertension and obesity.

Table: 1 Age wise distribution of hypertensives $(\mathrm{N}=1127)$

\begin{tabular}{|l|c|c|c|}
\hline AGE & TOTAL & HTN & \% \\
\hline $40-49$ & 426 & 82 & 19.2 \\
\hline $50-59$ & 294 & 119 & 40.5 \\
\hline $60-69$ & 261 & 107 & 41 \\
\hline$\geq 70$ & 146 & 71 & 48.6 \\
\hline TOTAL & 1127 & 379 & 33.6 \\
\hline
\end{tabular}

Table: 2 shows Distribution of Height above 40 years

\begin{tabular}{|l|c|c|c|c|}
\hline \multirow{2}{*}{ Height in cm } & \multicolumn{2}{|c|}{ Male } & \multicolumn{2}{c|}{ Female } \\
\cline { 2 - 5 } & No & $\%$ & No & $\%$ \\
\hline$<150$ & 34 & 6.5 & 417 & 69 \\
\hline $151-165$ & 351 & 67.1 & 185 & 30.6 \\
\hline$>166$ & 138 & 26.4 & 2 & 0.4 \\
\hline Total & 523 & 100 & 604 & 100 \\
\hline
\end{tabular}


Table: 3 Distribution of weight among $>40$ years

\begin{tabular}{|l|c|c|c|c|}
\hline \multirow{2}{*}{ Weight in kg } & \multicolumn{2}{|c|}{ Male } & \multicolumn{2}{c|}{ Female } \\
\cline { 2 - 5 } & No & $\%$ & No & $\%$ \\
\hline$<50$ & 103 & 19.6 & 254 & 42.0 \\
\hline $51-69$ & 344 & 65.7 & 296 & 49.0 \\
\hline$>70$ & 76 & 14.5 & 54 & 9.0 \\
\hline Total & 523 & 100 & 604 & 100 \\
\hline
\end{tabular}

Table 4: Correlation between BMI and Hypertension among males

\begin{tabular}{|l|c|c|c|c|c|c|c|}
\hline \multirow{2}{*}{ BMI } & \multirow{2}{*}{$(\mathrm{n})$} & \multicolumn{2}{|c|}{ Hypertensive } & \multicolumn{2}{|c|}{ Normotensive } & Chi-square value & P-value \\
\cline { 3 - 6 } & & No & $\%$ & No & $\%$ & & \\
\hline$<25$ & 367 & 84 & 22.9 & 283 & 77.1 & \multirow{2}{*}{22.68} & \multirow{2}{*}{$<0.001$} \\
\hline $25-30$ & 131 & 57 & 43.5 & 74 & 56.4 & & \\
\hline$>30$ & 25 & 11 & 44.0 & 14 & 56.0 & & \\
\hline Total & 523 & 152 & 29.1 & 371 & 70.9 & & \\
\hline
\end{tabular}

Table 5: Correlation between BMI and Hypertension among females

\begin{tabular}{|l|c|c|c|c|c|c|}
\hline \multirow{2}{*}{ BMI } & \multicolumn{2}{|c|}{ Hypertensive } & \multicolumn{2}{|c|}{ Normotensive } & Chi-square value & P-value \\
\cline { 2 - 5 } & No & $\%$ & No & $\%$ & & \\
\hline$<25$ & 95 & 27.4 & 252 & 72.6 & & \\
\hline $25-30$ & 78 & 48.4 & 83 & 51.6 & \multirow{2}{*}{37.7} & $<0.001$ \\
\hline$>30$ & 54 & 56.2 & 42 & 43.8 & & \\
\hline Total & 227 & 37.6 & 377 & 63.4 & & \\
\hline
\end{tabular}

Table 6: Association between hypertension and obesity

\begin{tabular}{|c|c|c|c|c|c|}
\hline & Hypertensive & Non-Hypertensive & Total & Odds Ratio & P-value \\
\hline Obese & 86 & 73 & 159 & \multirow{3}{*}{2.71} & \multirow{3}{*}{$\begin{array}{c}<\mathbf{0 . 0 5} \\
(1.92-3.81)\end{array}$} \\
\hline Non-obese & 293 & 675 & 968 & & \\
\hline Total & 379 & 748 & 1127 & & \\
\hline
\end{tabular}

\section{Discussion}

This study was conducted among rural population of 4116 in the sub-centre Kezh Bhuvanagiri, Chidambaram Taluk, Cuddalore District. The number of persons above 40 years of age were 1232. Out of which males were $48.9 \%$ and females were $51.1 \%$.

In this epidemiological study of hypertension, standardized methods were used in rural population. Up to $71 \%$ of the eligible subjects living in this area participated. This rural society, like many urban societies in developing countries, is undergoing a transition regarding pattern of diseases from traditionally infectious to chronic diseases which can be attributed to the adoption of westernized life style choices and increasing physical inactivity. The economic development and the consequent life style changes form the major reasons for the emergence of hypertension in the rural societies of developing countries. This study has attempted to show that the rural population has becomes obese. Hypertension compounded with obesity will become a major public health problem in these communities and can result in increased morbidity and mortality.

In females less than $50 \mathrm{~kg}, 71(27.9 \%)$ were hypertensive. In 51-69 kg, 117 (39.5\%) were hypertensive. In the more than $70 \mathrm{~kg}, 39(72.2 \%)$ were hypertensive. This study shows that as weight increases hypertension also increases. As seen in the Table 4,5 and 6 it could be noted that in both the sex, prevalence of hypertension increases with increasing weight. This is in accordance with other studies carried out by Gupta $^{8}$, Joshi ${ }^{9}$, Whelton ${ }^{10}$, Kannel ${ }^{11}$, and Chiang ${ }^{12}$.

From Table 4,5 and 6 it was seen that as BMI increases prevalence of hypertension also increases. The relation between BMI and hypertension has been studied by many investigators, namely Shaper ${ }^{13}$, Malhothra ${ }^{14}$, Joshi $^{9}$ and they all concluded in the same way. In 
males less than 25 BMI, 84 (22.9\%) were hypertensive. Among 25 - 30 BMI, 57(43.5\%) were hypertensive more than 30 BMI 11 (44\%) were hypertensive. In females less than $25 \mathrm{BMI}$, $95(27.4 \%)$ were hypertensive. In the range of 25 30 BMI, 78 (48.4\%) were hypertensive. In more than 30 BMI, 54(56.2\%) were hypertensive. This shows that as the BMI increases hypertension also increases.

\section{Conclusion}

The present study was a cross sectional study which was undertaken among rural population in the Kezh Bhuvanagiri, Chidambaram Taluk, Cuddalore District. This study confirms that hypertensionis emerging as an important public health problem among those who are 40 years and above. It has been well established that as the rural population becomes obese, physically inactive, with high sodium intake and stress levels, the problem is equally assuming importance in rural communities also. In the present study it has been noted that more number of females $(37.5 \%)$ were hypertensive as compared to males (29.0\%). Further it has been found that as age increases hypertension also increases. It has been proved categorically that as BMI increases hypertension also increases.

\section{References}

1. WHO, TRS No. 686, 1983. 'Primary prevention of essential hypertension' report of WHO scientific group.

2. WHO, 1998 'Life in the $21^{\text {st }}$ century: A vision for all'. A WHO report 1998. Geneva, 241.

3. Sunday express supplement. 'The silent killer'. Indian express newspaper dated 4\3\2000 pp18.

4. Rajeev Gupta, Hypertension in Indiadefinition- prevalence and evaluation JIMA, Vol.97, No.1, March 1991 pp 7479.
5. ICMR (1991) ' progress in cardiovascular disease research in India during the last two decades (1971-1991)' Bulletin, Vol.22, April 1992.

6. Stamler R, et al. JAMA 1976.

7. Janeway J.C. A clinical study of hypertensive cardiovascular diseases. Arch.Internal Medicine 1993, pp 755-798.

8. Gupta S.P. et al., 'Hypertension and its trends in the general population of Haryana' J. of Association of Physicians of india, Feb 1979, Vol. 27, pp 119-126.

9. Joshi P.P., Kate. S.K., Shegokar.V. Blood pressure trends and life style risk factors in rural India. J. of Association of physician of india, 1993, Vol. 41, pp 579581.

10. Whelton P.K.et al., J. of Hum Hypertension, Feb 2000, pp 544-549.

11. Kannel W. B., Brand N. et al., The relationship of adiposity to blood pressure and development of hypertension. The Framigham Study. Am. Intern, Med.1967.

12. Chiang B.N., Perlman LV., Epstein F.H., Overweight and hypertension. Am int. Med. 1989, 403-421.

13. Shaper AG et al., Blood Pressure in middle aged British Men J. Hum Hypertension 1988, 71-80.

14. P.Malhothra et al., Journal of Human Hypertension, July 1999, pp 467-472. 